\title{
Transcription Factor AP-1 Modulates the Activity of the Human Foamy Virus Long Terminal Repeat
}

\author{
BERND MAURER,* EDGAR SERFLING, VOLKER TER MEULEN, AND AXEL RETHWILM \\ Institut für Virologie und Immunbiologie, Universität Würzburg, Versbacher Strasse 7, \\ 8700 Würzburg, Germany
}

Received 26 April 1991/Accepted 16 August 1991

\begin{abstract}
The human foamy virus (HFV) contains within the U3 region of its long terminal repeat (LTR) three perfect consensus sequences for the binding of the inducible transcription factor AP-1. Results of DNase I footprint protection and gel retardation assays demonstrated that proteins in extracts of HeLa and BHK-21 cells as well as bacterially expressed Jun and Fos proteins bind to these AP-1 sites. By conducting transient expression assays using chloramphenicol acetyltransferase plasmids carrying LTR sequences with point-mutated AP-1 sites, it was found that the three AP-1 sites contribute to the optimal activity of the HFV promoter. It is shown that induction of the HFV LTR by 12-O-tetradecanoylphorbol-13-acetate (TPA) and serum factors is mediated through the AP-1 sites.
\end{abstract}

The human foamy virus (HFV) is a member of the third subfamily of exogenous retroviruses, the Spumavirinae (31). Molecular cloning and nucleotide sequence analysis of HFV have led to an increased interest in this virus groups $(6,17$, 25,32 ). In addition to gag, pol and env, HFV bears three open reading frames, located between the env gene and the $3^{\prime}$ long terminal repeat (LTR), which were proposed to have regulatory functions $(6,18,19)$. Recently, it has been demonstrated that one of the three $3^{\prime}$ open reading frames, bell, encodes a transcriptional transactivator $(12,26)$. Similar results have been reported for the related simian foamy virus type 1 (SFV-1), isolated from the rhesus macaque $(21,22)$. The transactivators of foamy viruses act at the DNA level on a sequence in the $U 3$ region of the viral $\operatorname{LTR}(12,22,26)$.

The LTRs of the two sequenced foamy viruses are among the longest LTRs of the retrovirus family. U3 is $777 \mathrm{bp}$ long in HFV and 1,296 bp long in SFV-1 $(17,21)$. Whereas SFV1 and HFV show about $80 \%$ nucleic acid similarity in the R and $\mathrm{U} 5$ regions, their $\mathrm{U} 3$ regions are highly divergent $(17$, 21). Furthermore, little is known about cis-acting sequences in the $\mathrm{U} 3$ regions of foamy viruses.

In the course of studies on the HFV promoter, we noted three perfectly conserved binding sites for the transcription factor AP-1 (5'-TGACTCA-3') which are not present in the SFV-1 promoter $(17,21)$ (Fig. 1). AP-1, first isolated from HeLa cell extracts $(2,15)$, regulates the activity of a variety of cellular and viral genes $(3,16,28,29)$. Because of their responsiveness to 12-O-tetradecanoylphorbol-13-acetate (TPA), the AP-1 sites are also referred to as TPA responsive elements (TREs) $(2,11,14)$. AP- 1 was shown to be a protein complex composed of the products of the jun and fos oncogene family (4). The Fos-Jun heterodimer binds to the TRE with high affinity, while the individual constituents of the AP-1 complex bind with a lower affinity (Jun) or not at all (Fos) $(8,13)$.

Since the binding of AP-1 to its target sequence was shown to modulate the transcription of several genes, we wanted to know whether AP-1 or AP-1-like factors bind to the HFV TREs and exert an effect on the promoter activity of HFV. Whole cellular extracts were prepared from HeLa and baby

\footnotetext{
* Corresponding author.
}

hamster kidney cells (BHK-21) as described previously (30). Additionally, bacterially expressed Jun and Fos proteins were used in DNA-protein interaction analysis. The $0.6-\mathrm{kbp}$ NcoI-BamHI fragment of pSVjun (1), comprising the DNA binding domain and the leucine zipper of $v$-Jun, was inserted into the StuI site of the bacterial expression vector pROS (5) in frame to the $\beta$-galactosidase coding sequence. For the expression of v-Fos, a 760-bp BglII-NcoI fragment of pTZJM containing the DNA binding domain and the leucine zipper of v-Fos was introduced into the EcoRV site of pROS. The fusion proteins were purified from induced BMH 71-18 bacteria (5) by two cycles of preparative sodium dodecyl sulfate-polyacrylamide gel electrophoresis. An extract of Escherichia coli expressing c-Jun as TrpE fusion protein was used as described previously (1). DNase I footprinting reactions and gel retardation assays were performed essentially as reported previously $(11,30)$. The BstEII-HindIII (-571 to -361$)$ fragment of the HFV LTR was radioactively labeled at either strand and assayed with partially purified whole cellular extracts from HeLa and BHK-21 cells or with bacterially expressed v-Jun and c-Jun. As shown in Fig. 2, proteins from both cell types as well as v-Jun and c-Jun efficiently protect the TREs of the HFV LTR against DNase digestion. The protected regions spanned about 15 nucleotides and were centered around the palindromic TREs but included flanking sequences as well.

The binding specificity of AP-1 to the target sequences in the HFV LTR was further analyzed by gel retardation and competition assays. As shown in Fig. $3 \mathrm{~A}$, the band generated by the labeled BstEII-HindIII fragment was shifted upon incubation with partially purified whole cellular extract from BHK-21 cells as well as with bacterially expressed c-Jun plus v-Fos. The fragment was also shifted upon incubation with the bacterially expressed Jun only, but the band appeared somewhat weaker, which might indicate the lower DNA binding activity of the Jun homodimer compared with that of the Jun-Fos heterodimer. As expected, no DNA binding was observed when the bacterially expressed v-Fos protein was assayed. Shifting of the labeled BstEII-HindIII fragment was abolished when the extract was incubated with a $10^{2}$-fold molar excess of unlabeled fragment (specific competitor) or a $10^{4}$ - to $10^{5}$-fold molar excess of poly(dI-dC) (unspecific competitor). 


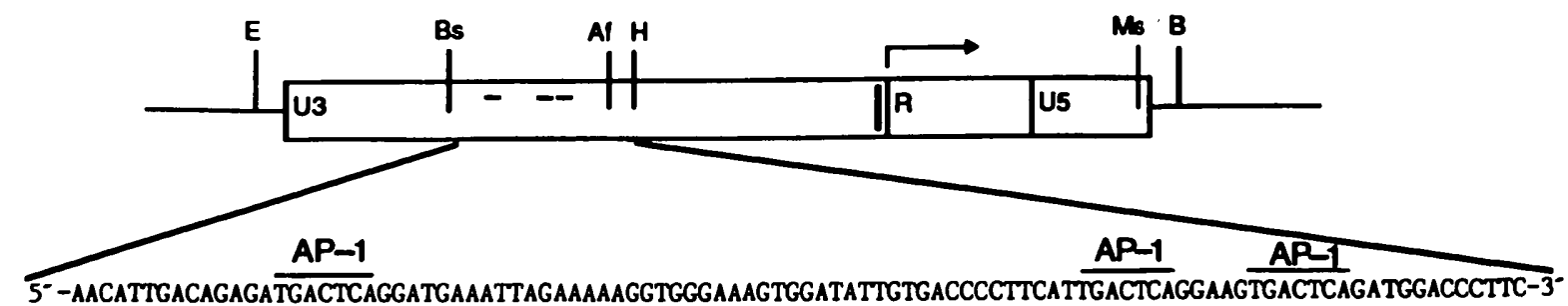

FIG. 1. Localization of the TREs within the LTR of HFV. The structure of the EcoRI-BamHI fragment of plasmid p5'LTR, spanning the complete 5' LTR of HFV, and the nucleotide sequence from positions -527 to -428 with respect to the start of transcription are shown. The start of transcription is marked by an arrow and the three TREs are marked by lines. The TATA box is marked by a bold stroke. Abbreviations: Af, AfII ; B, BamHI; Bs, BstEII; E, EcoRI; H, HindIII; Ms, MstII

It has been reported recently that the AP-1 binding sites in the visna virus LTR contribute significantly to its basal and transactivator-mediated activity (9). We studied the possibility that the AP-1 sites in the HFV LTR play a similar functional role. $\mathrm{p}^{\prime}$ cat $(-571 /+325)$ and $\mathrm{p} 5{ }^{\prime}$ cat $(-376 /+325)$

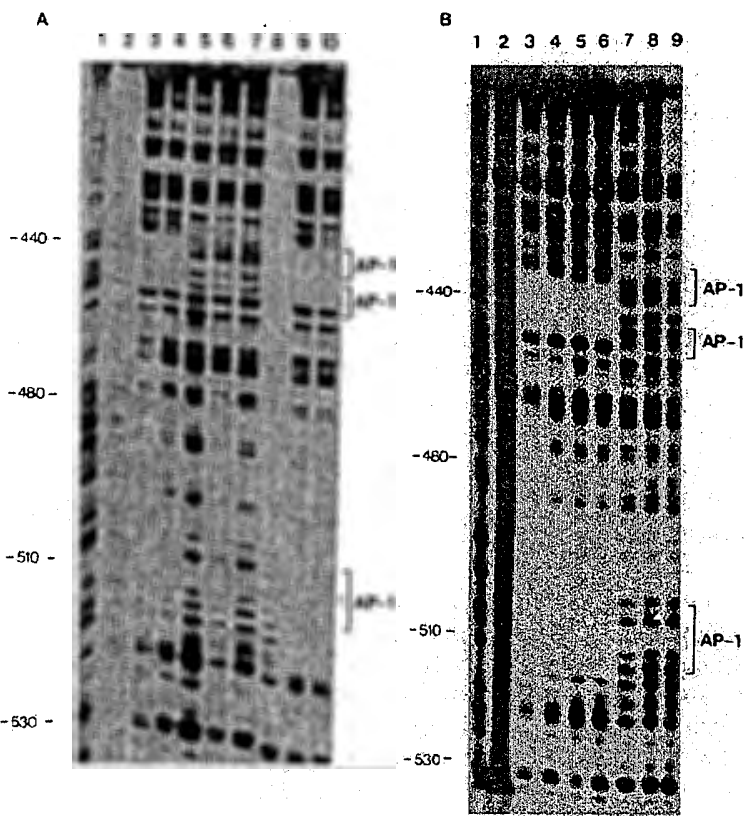

FIG. 2. DNase footprint protection analysis of both strands of the BstEII-HindIII fragment of the HFV LTR. (A) The plus strand was end labeled with polynucleotide kinase at the BstEII $(-571)$ site of the fragment, incubated with $5 \mu \mathrm{g}$ of bacterially expressed c-Jun (lane 3) or v-Jun (lane 4) or with $50 \mu \mathrm{g}$ of partially purified extracts from HeLa cells (lane 9) or BHK-21 cells (lane 10), and subjected to DNase I footprinting reactions; control reactions were with $10 \mu \mathrm{g}$ (lane 6) and $50 \mu \mathrm{g}$ (lane 7) of bovine serum albumin (BSA), no protein (lanes 5 and 8), 10× DNase I (lane 8), and G-specific (lane 2) and $\mathrm{G}+\mathrm{A}$-specific (lane 1 ) sequence reactions (20). (B) The minus strand was end labeled with Klenow enzyme at the BstEII $(-571)$ site of the fragment and incubated with $5 \mu g$ of bacterially expressed c-Jun (lane 3) or v-Jun (lane 4) or with $50 \mu \mathrm{g}$ of partially purified extracts from HeLa cells (lane 5) or BHK-21 cells (lane 6); control reactions were without protein (lane 7) and with $10 \mu \mathrm{g}$ (lane 8) and $50 \mu \mathrm{g}$ (lane 9) of BSA and G-specific (lane 1) and G+A-specific (lane 2) sequence reactions. The protected AP-1 sites are marked with brackets. The numbers indicate the nucleotide positions with respect to the start of transcription. were constructed by the insertion of $B g$ III linkers into the SauI site at position +325 relative to the start of transcription and into the $B s t$ EII site (position -571) or the AflI site (position -376). Respective BglII fragments were then cloned into pOcat-Bg (27). Oligonucleotide-directed in vitro mutagenesis of the AP-1 binding sites was performed on the HFV LTR inserted into the M13mp19 vector as an EcoRI$B a m H I$ fragment by using the Amersham in vitro mutagenesis system (Amersham-Buchler, Braunschweig, Germany) and chemically synthesized oligonucleotides with mutated AP-1 sites, as shown in Table 1. BglII fragments of appropriate mutants were inserted into pOcat- $\mathrm{Bg}$, giving rise to plasmids p5'cat-Mu1 to $55^{\prime}$ cat-Mu6 (Table 1). The activity of LTR-chloramphenicol acetyltransferase (CAT) constructs with, without, and with point-mutated AP-1 sites was determined by transient transfections of BHK-21 cells, and subsequent CAT assays were performed as described recently (26). As shown in Table 1 and consistent with previously reported results, the wild-type LTR was almost silent in BHK-21 cells if the cells were not cotransfected with the HFV-specific transactivator, bell (26). Hence, all further assays were performed by cotransfection of pSbell-S, a plasmid expressing the HFV transactivator in eukaryotic cells (26). Mutations of any of the three TREs (in plasmids $\mathrm{p}^{5}$ 'cat-Mu1 to p5'cat-Mu4 in Table 1) led to a decrease in CAT gene expression (about 25 to $30 \%$ ) directed by the HFV LTR compared with wild-type LTR activity. A further drop in protein expression, to about $60 \%$ of the level of the wild-type LTR activity, was observed when an LTR-CAT construct with mutations of the two downstream AP-1 sites (p5'cat-Mu5) was used. No further significant reduction of CAT activity was observed when all three TREs were either mutated (p5'cat-Mu6) or deleted [p5'cat $(-376 /+325)]$.

To show that the reduction in functional activity of the mutated LTR is reflected by a lower binding affinity to AP-1-like factors, we performed gel retardation assays. As shown in Fig. 3B, the mutation of any one of the AP-1 sites (in plasmids p5'LTRMul to p5'LTRMu4) led to a faster migration rate of the respective BstEII-HindIII LTR fragment. This was even more pronounced when a BstEIIHindIII LTR fragment with the two mutated downstream AP-1 sites (p5'LTR-Mu5) was used, and no retardation was observed when all three AP-1 sites were mutated ( $p 5^{\prime}$ LTRMu6).

To study the influence of TPA on the gene expression directed by the HFV LTR, we investigated the CAT expression of wild-type p5'cat $(-571 /+325)$, p5'cat-Mul (first AP-1 site mutated), and p5'cat-Mu6 (all three AP-1 sites mutated) upon cotransfection with pSbell-S in the presence of different concentrations of TPA. As shown in Table 2, the 
A

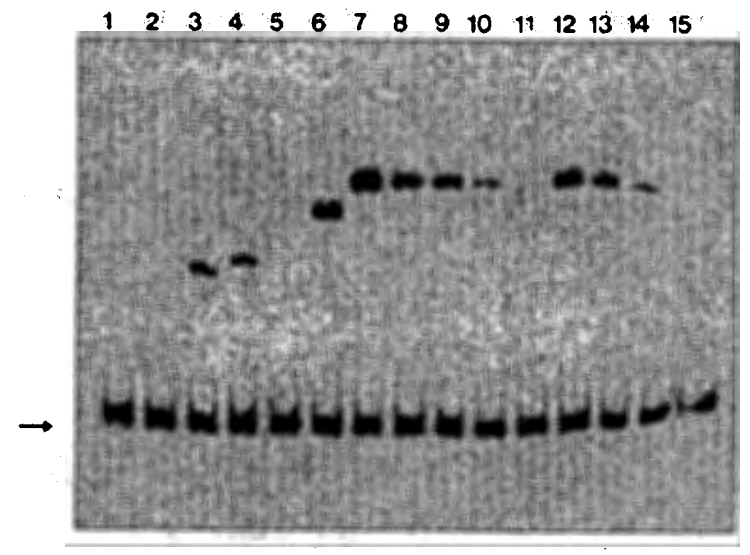

B

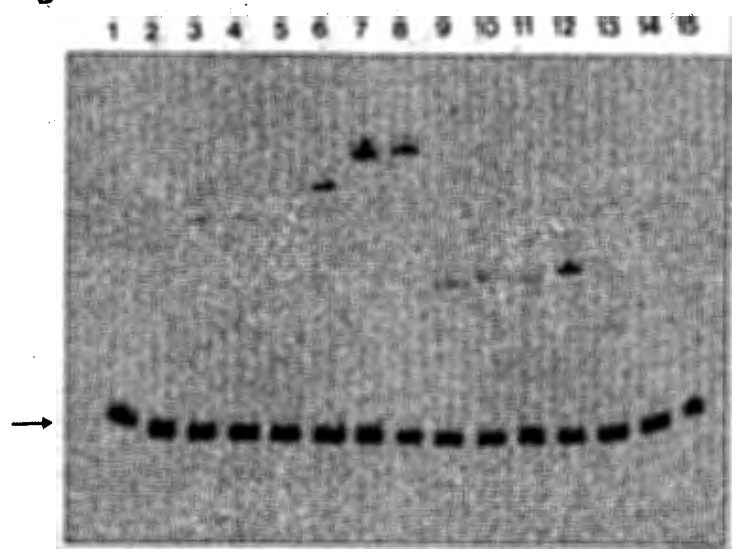

induction of wild-type LTR is stimulated threefold at a TPA concentration of $50 \mathrm{ng} / \mathrm{ml}$ compared with induction in TPAfree medium. At the same TPA concentration, $\mathrm{p} 5{ }^{\prime}$ cat-Mul is stimulated about 1.7 -fold, and no significant stimulation with p5'cat-Mu6 was observed. When the growth factor responsiveness of the HFV LTR gene expression driven by the HFV was tested, it was found that wild-type LTR could
FIG. 3. Gel retardation and competition assay. (A) The end labeled DNA fragment was incubated with $2.5 \mu \mathrm{g}$ of bacterially expressed v-Jun (lane 3), c-Jun (lane 4), v-Fos (lane 5), or c-Jun-vFos (lane 6) or with $20 \mu \mathrm{g}$ of BHK-21 cell extract (lanes 7 to 15) and increasing amounts of competitors and separated on a nondenaturing polyacrylamide gel. The molar ratio of the labeled fragment to specific competitor was 1:1 (lane 8), 1:5 (lane 9), 1:20 (lane 10), or $1: 100$ (lane 11). The ratio of the labeled fragment to unspecific

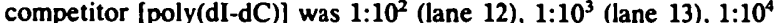
(lane 14), or $1: 10^{5}$ (lane 15). Control reactions were without protein (lane 1) or with $5 \mu \mathrm{g}$ of BSA (lane 2). (B) Reaction of the BstEII-HindIII fragment with $2.5 \mu \mathrm{g}$ of bacterially expressed v-Jun (lane 3), c-Jun (lane 4), v-Fos (lane 5), or v-Jun-v-Fos (lane 6) or with $25 \mu \mathrm{g}$ of HeLa (lane 7) or BHK-21 (lanes 8 to 14) cell extract. Fragments with mutations, as shown in Table 1, are Mul (lane 9), Mu2 (lane 10), Mu3 (lane 11), Mu4 (lane 12), Mus (lane 13), and Mu6 (lane 14). Arrows indicate free DNA.

clearly be enhanced by increasing the serum concentration in the medium (Table 2). This activation was less pronounced with $\mathrm{p} 5$ 'cat-Mul and hardly demonstrable with p5'cat-Mu6. When the three indicator plasmids were cotransfected with pUC DNA instead of pSbell-S at either high TPA or high serum concentration, only the low basal HFV promoter activity was observed.

The experiments reported here show that AP-1 or an AP-1-like factor present in HeLa cells and BHK-21 cells binds to the three TREs within the HFV LTR. It is most likely that the binding factor in the partially purified cellular extracts corresponds to the transcription factor AP-1, because (i) in the DNase I footprint protection analysis (Fig. 2), the same protection patterns were observed for the cellular extracts and bacterially expressed v-Jun or c-Jun protein; (ii) as shown by competition assays, the binding of the cellular factors to the AP-1 sites is specific (Fig. 3A); and (iii) this specific binding was further demonstrated by analyzing LTR fragments with mutated AP-1 sites in bandshift assays (Fig. 3B). However, the results of our experiments do not completely rule out the formal possibility that cellular factors other than the c-Jun-c-Fos complex also bind to the TREs of HFV. The cellular CREB protein, for example, recognizes both the cyclic AMP responsive element and the AP-1 target sequence $(10,24)$. The CREB binding site differs from the AP-1 site only in the addition of a central C-G base pair (7, 24). Furthermore, it has been shown that the AP-1 site in the gibbon ape leukemia virus promoter is recognized by a

TABLE 1. Relative promoter activities of wild-type and mutated HFV LTR-CAT constructs

\begin{tabular}{|c|c|c|}
\hline Construct & Sequence $^{a}$ & Relative CAT activity (\%) \\
\hline 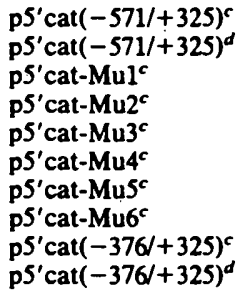 & 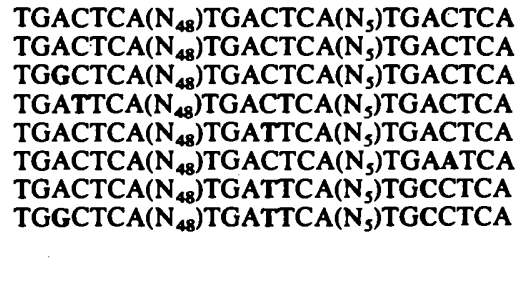 & $\begin{aligned} 100.0 & \pm 0.0 \\
1.2 & \pm 0.9 \\
71.1 & \pm 4.2 \\
72.9 & \pm 2.2 \\
75.5 & \pm 2.4 \\
76.2 & \pm 3.9 \\
61.3 & \pm 1.6 \\
58.7 & \pm 1.9 \\
61.3 & \pm 2.7 \\
1.8 & \pm 1.1\end{aligned}$ \\
\hline
\end{tabular}

Mutated nucleotides are in boldface.

- Mean and standand deviation of six independent transfections.

- Cotransfected with pSbell-S.

d Cotransfected with pUC DNA. 
TABLE 2. Induction of wild-type and mutated HFV LTR by TPA and serum factors

\begin{tabular}{|c|c|c|c|c|}
\hline \multirow[b]{2}{*}{ Construct } & \multicolumn{2}{|c|}{$\begin{array}{c}\text { Induction by } \\
\text { TPA }^{a}\end{array}$} & \multicolumn{2}{|c|}{$\begin{array}{l}\text { Induction by fetal } \\
\text { calf serum }\end{array}$} \\
\hline & $\begin{array}{c}\text { TPA } \\
\text { concn } \\
(\mathrm{mg} / \mathrm{ml})\end{array}$ & $\begin{array}{c}\text { Relative } \\
\text { CAT activity } \\
(\%)^{c}\end{array}$ & $\begin{array}{l}\text { Fetal calf } \\
\text { serum } \\
(\%)\end{array}$ & $\begin{array}{c}\text { Relative } \\
\text { CAT activity } \\
(\%)^{*}\end{array}$ \\
\hline $\mathrm{p}^{\prime}$ cat $(-571 /+325)^{d}$ & $\begin{array}{r}0.0 \\
2.5 \\
10.0 \\
50.0\end{array}$ & $\begin{aligned} 100.0 & \pm 0.0 \\
97.8 & \pm 4.4 \\
172.0 & \pm 6.3 \\
298.3 & \pm 5.7\end{aligned}$ & $\begin{array}{r}0.5 \\
2.5 \\
5.0 \\
10.0\end{array}$ & $\begin{aligned} 58.0 & \pm 5.0 \\
79.4 & \pm 6.0 \\
100.0 & \pm 0.0 \\
106.3 & \pm 5.3\end{aligned}$ \\
\hline $\begin{array}{l}\mathrm{p} 5^{\prime} \mathrm{cat}(-571 /+325)^{e} \\
\mathrm{p}^{\prime}{ }^{\prime c a t}-\mathrm{Mul}^{d}\end{array}$ & $\begin{array}{r}50.0 \\
0.0 \\
2.5 \\
10.0 \\
50.0\end{array}$ & $\begin{aligned} 2.6 & \pm 2.4 \\
64.1 & \pm 3.7 \\
62.3 & \pm 5.1 \\
88.4 & \pm 4.2 \\
104.0 & \pm 6.2\end{aligned}$ & $\begin{array}{r}10.0 \\
0.5 \\
2.5 \\
5.0 \\
10.0\end{array}$ & $\begin{array}{r}2.2 \pm 1.6 \\
49.4 \pm 4.2 \\
54.2 \pm 3.6 \\
52.0 \pm 2.0 \\
58.5 \pm 4.2\end{array}$ \\
\hline $\begin{array}{l}\text { p5'cat-Mule } \\
\text { p5'cat-Mu6 }\end{array}$ & $\begin{array}{r}50.0 \\
0.0 \\
2.5 \\
10.0 \\
50.0\end{array}$ & $\begin{array}{r}2.0 \pm 1.9 \\
57.6 \pm 5.0 \\
58.8 \pm 3.2 \\
53.6 \pm 4.2 \\
59.4 \pm 3.8\end{array}$ & $\begin{array}{r}10.0 \\
0.5 \\
2.5 \\
5.0 \\
10.0\end{array}$ & $\begin{array}{r}2.6 \pm 2.1 \\
50.1 \pm 3.7 \\
52.4 \pm 2.1 \\
54.3 \pm 2.6 \\
56.2 \pm 3.2\end{array}$ \\
\hline $\mathrm{pS}^{\prime} \mathrm{cat}^{-M u 6^{e}}$ & 50.0 & $2.9 \pm 2.7$ & 10.0 & $1.9 \pm 1.4$ \\
\hline
\end{tabular}

a TPA treatment was for $5 \mathrm{~h}$ prior to harvest of the transfected cells in medium containing $0.5 \%$ fetal calf serum.

b Transfected cells were kept in medium containing fetal calf serum at the indicated concentrations for $20 \mathrm{~h}$ prior to harvest.

c Mean and standard deviation of six independent transfections.

d Cotransfected with pSbell-S.

- Cotransfected with pUC DNA.

complex unrelated to Jun or Fos protein in certain cell lines (23).

The activity of the HFV promoter was found to depend mainly on the transactivator bell. However, as demonstrated by transient transfections and subsequent CAT assays using constructs with mutated or deleted AP-1 sites, the full promoter activity is only obtained with functionally intact AP-1 binding sites. Since constructs with defective or deleted TREs achieved approximately $60 \%$ of the wild-type promoter activity, it is likely that the proposed target sequence of the bell transactivator in the $\mathrm{U} 3$ region of the HFV LTR is not located within the BstEII-HindIII fragment ( -571 to -361 ) harboring the AP-1 binding sites or further upstream. This assumption is consistent with recently published data on the preliminary mapping of the bell target sequence (12). Furthermore, this result demonstrates that the mechanism of bell-mediated transactivation differs from that of visna virus, in which an AP-1 site close to the TATA box seems to be one major target for the transactivator (9). Our experiments suggest that, as in some lentiviruses, the transactivator is essential for HFV replication whereas cellular factors, such as AP-1, modulate viral transcription in response to extracellular stimuli.

When the HFV AP-1 mutants were tested in cells grown in media with different serum concentrations, we also found the AP-1 sites to be targets for the serum response. Similar results were obtained when TPA induction was analyzed. Responsiveness to serum factors and TPA is a known characteristic of AP-1 elements $(2,11,14)$. As is shown for serum responsiveness, the induction of the HFV LTR by TPA seems to correlate with the copy numbers of intact TREs.

The data presented here suggest that regulation of HFV transcription differs from that of other retroviruses. Apart from the TREs and the TATA box, there are no known consensus sequences for transcription factors for the LTRs of other retroviruses. It is likely that other cellular factors whose target sequences are yet unknown contribute to the transcriptional regulation of HFV, implicating $\mathrm{HFV}$ as a system for further investigation of the molecular mechanism of retroviral gene regulation.

We thank P. Angel for bacterially expressed trpE-cJun fusion protein, R. Müller for providing plasmid pTZJM, A. Plückthun for the gift of pROS vector, S. Siddell for oligonucleotide synthesis, and J. Clements for critical reading of the manuscript. We thank $\mathrm{H}$. Kriesinger for typing the manuscript.

This work was supported by the Bundesministerium für Forschung und Technologie and by the Deutsche Forschungsgemeinschaft.

\section{REFERENCES}

1. Angel, P., E. A. Allegretto, S. T. Okino, K. Hattori, W. J. Boyle, T. Hunter, and M. Karin. 1988. Oncogene jun encodes a sequence-specific trans-activator similar to AP-1. Nature (London) 332:166-171

2. Angel, P., M. Imagawa, R. Chiu, B. Stein, R. J. Imbra, H. J. Rahmsdorf, C. Jonat, P. Herrlich, and M. Karin. 1987. Phorbol ester-inducible genes contain a common cis element recognized by a TPA-modulated trans-acting factor. Cell 49:729-739.

3. Chiu, R., W. J. Boyle, J. Meek, T. Smeal, T. Hunter, and M. Karin. 1988. The c-Fos protein interacts with c-Jun/AP-1 to stimulate transcription of AP-1 responsive genes. Cell 54:541552.

4. Curran, T., and B. R. Franza, Jr. 1988. Fos and Jun: The AP-1 connection. Cell 55:395-397.

5. Ellinger, S., R. Glockshuber, G. Jahn, and A. Plückthun. 1989. Cleavage of procaryotically expressed human immunodefciency virus fusion proteins by factor $\mathbf{X}_{\mathbf{a}}$ and application in Western blot (immunoblot) assays. J. Clin. Microbiol. 27:971976.

6. Flügel, R. M., A. Rethwilm, B. Maurer, and G. Darai. 1987. Nucleotide sequence analysis of the env gene and its flanking regions of the human spumaretrovirus reveals two novel genes. EMBO J. 6:2077-2084.

7. Hai, T., F. Liu, E. A. Allegretto, M. Karin, and M. R. Green. 1988. A family of immunologically related transcription factors that includes multiple forms of ATF and AP-1. Genes Dev. 2:1216-1226.

8. Halazonetis, T. D., K. Georgopoulos, M. E. Greenberg, and P. Leder. 1988. c-Jun dimerizes with itself and with c-Fos, forming complexes of different DNA binding affinities. Cell 55:917-924.

9. Hess, J. L., J. A. Small, and J. E. Clements. 1989. Sequences in the visna virus long terminal repeat that control transcriptional activity and respond to viral trans-activation: involvement of AP-1 sites in basal activity and trans-activation. J. Virol. 63:3001-3015.

10. Hoefifer, J. P., T. E. Meyer, Y. Yun, L. J. Jameson, and J. F. Habener. 1988. Cyclic AMP-responsive DNA-binding protein: structure based on a cloned placental cDNA. Science 242:14301433.

11. Imagawa, M., R. Chiu, and M. Karin. 1987. Transcription factor AP-2 mediates induction by two different signal-transduction pathways: protein kinase $C$ and cAMP. Cell 51:251-260.

12. Keller, A., K. M. Partin, M. Löchelt, H. Bannert, R. M. Flügel, and B. R. Cullen. 1991. Characterization of the transcriptional trans-activator of human foamy retrovirus. J. Virol. 65:2589 2594.

13. Kouzarides, T., and E. Ziff. 1988. The role of the leucine zipper in the fos-jun interaction. Nature (London) 336:646-651.

14. Lee, W., A. Haslinger, M. Karin, and R. Tjian. 1987. Activation of transcription by two factors that bind promoter and enhancer sequences of the human metallothionein gene and SV40. Nature (London) 325:368-372.

15. Lee, W., P. Mitchell, and R. Tjian. 1987. Purified transcription factor AP-1 interacts with TPA-inducible enhancer elements. Cell 49:741-752.

16. Lucibello, F. C., M. Neuberg, J. B. Hunter, T. Jenuwein, M. 
Schuermann, R. Wallich, B. Stein, A. Schönthal, P. Herrlich, and R. Müller. 1988. Transactivation of gene expression by fos protein: involvement of a binding site for the transcription factor AP-1. Oncogene 3:43-51.

17. Maurer, B., H. Bannert, G. Darai, and R. M. Flügel. 1988. Analysis of the primary structure of the long terminal repeat and the $\mathrm{gag}$ and pol genes of the human spumaretrovirus. J. Virol. 62:1590-1597.

18. Maurer, B., and R. M. Flügel. 1987. The 3' orf protein of human immunodeficiency virus 2 shows sequence homology with the bel 3 gene of the human spumaretrovirus. FEBS Lett. 222:286288.

19. Maurer, B., and R. M. Flügel. 1988. Genomic organization of the human spumaretrovirus and its relatedness to AIDS and other retroviruses. AIDS Res. Hum. Retroviruses 4:467-473.

20. Maxam, A. M., and W. Gilbert. 1977. A new method for sequencing DNA. Proc. Natl. Acad. Sci. USA 74:560-564.

21. Mergia, A., K. E. S. Shaw, E. Pratt-Lowe, P. A. Barry, and P. A. Luciw. 1990. Simian foamy virus type 1 is a retrovirus which encodes a transcriptional transactivator. J. Virol. 64:3598-3604.

22. Mergia, A., K. E. S. Shaw, E. Pratt-Lowe, P. A. Barry, and P. A. Luciw. 1991. Identification of the simian foamy virus transcriptional transactivator gene (taf). J. Virol. 65:2903-2909.

23. Quinn, J. P., A. R. Farina, K. Gardner, H. Krutzsch, and D. Levens. 1989. Multiple components are required for sequence recognition of the AP-1 site in the gibbon ape leukemia virus enhancer. Mol. Cell. Biol. 9:4713-4721.

24. Ransone, L. J., P. Wamsley, K. L. Morley, and I. M. Verma. 1990. Domain swapping reveals the modular nature of Fos, Jun, and CREB proteins. Mol. Cell. Biol. 10:4565-4573.
25. Rethwilm, A., G. Darai, A. Rösen, B. Maurer, and R. M. Flügel. 1987. Molecular cloning of the genome of human spumaretrovirus. Gene 59:19-28.

26. Rethwilm, A., O. Erlwein, G. Baunach, B. Maurer, and V. ter Meulen. 1991. The transcriptional transactivator of human foamy virus maps to the bel 1 genomic region. Proc. Natl. Acad. Sci. USA 88:941-945.

27. Rethwilm, A., K. Mori, B. Maurer, and V. ter Meulen. 1990. Transacting transcriptional activation of human spumaretrovirus LTR in infected cells. Virology 175:568-571.

28. Sassone-Corsi, P., L. J. Ransone, W. W. Lamph, and I. M. Verma. 1988. Direct interaction between Fos and Jun nuclear oncoproteins: role of the 'leucine zipper' domain. Nature (London) 336:692-695.

29. Schönthal, A., P. Herrlich, H. J. Rahmsdorf, and H. Ponta. 1988. Requirement for fos gene expression in the transcriptional activation of collagenase by other oncogenes and phorbol esters. Cell 54:325-334.

30. Serfling, E., R. Barthelmäs, I. Pfeufier, B. Schenk, S. Zarius, R. Swoboda, F. Mercurio, and M. Karin. 1989. Ubiquitous and lymphocyte-specific factors are involved in the induction of the mouse interleukin 2 gene in $\mathrm{T}$ lymphocytes. EMBO J. 8:465473.

31. Teich, N. 1984. Taxonomy of spumaviruses, p. 157-163. In R. A. Weiss, N. Teich, H. Varmus, and J. Coffin (ed.), Tumor viruses, vol. 1. Cold Spring Harbor Laboratory, Cold Spring Harbor, N.Y.

32. Weiss, R. A. 1988. A virus in search of a disease. Nature (London) 333:497-498. 